\title{
Multiparametric comparative analysis of coelomocytes in Asterias amurensis and Lysastrosoma anthosticta
}

\section{Yuriy Karetin and Eugenia Pimenova}

A. V. Zhirmunsky Institute of Marine Biology, National Scientific Center of Marine Biology, Far Eastern Branch, Russian Academy of Sciences. Palchevskogo Str, 17, Vladivostok, 690041, Russian Federation

Address correspondence and requests for materials to Yuriy Karetin, yura15cbx@gmail.com

\begin{abstract}
Behavioral dynamics of coelomocytes from echinoderms Asterias amurensis and Lysastrosoma anthosticta during the first hour of in vitro cultivation was analyzed using a wide range of linear and fractal parameters of the external morphology. Most of the parameters, including values of the cell bounding circle and convex hull, asymmetry, fractal dimensions of contour images, lacunarity, and cell density and area, showed species-specific behavior of the immune cells of the studied animals. The cells differed in a wide range of parameters as early as two min after seeding on the substrate. The cells acquired the largest morphological differences by the fifth min of cultivation. Both cell dynamics in general and analysis of the cell morphology at individual points in time may serve as markers for species-specificity of cells. However, when morphology is compared at one point in time, at least two parameters associated with significant morphological differences in cells of the studied species should be used because of overlapping tendencies in changes in morphological features.
\end{abstract}

Keywords: Asterias amurensis, Lysastrosoma anthosticta, coelomocytes, morphometry, fractal analysis, cell morphology.

\section{Introduction}

Hemolymph and coelomic fluid cells of invertebrates perform a protective function that is implemented as variants of a single systemic cell response to a foreign body: phagocytosis of microscopic foreign particles detected by the cell; encapsulation - in vivo spreading of the cell over a foreign body too large to be engulfed by the cell; in vitro spreading of the cell over the substrate to isolate the foreign surface significantly exceeding the cell area (Ratner and Vinson, 1983). All these reactions have a common mechanism including recognition of the foreign surface, adhesion to it, and a directed change in the cell motility and shape. Peculiarities of the cell response to the external environment are particularly noticeable when the cell spreads over a two-dimensional substrate because the biochemical and topologically unified environment of the in vitro-spread cell enables identification of the type-specific (Karetin and Pushchin, 2015, 2017) and speciesspecific (Karetin, 2016) characteristics of cell behavior as well as its natural or experimentally-induced abnormalities (Kalitnik et al., 2017).

In general, Asteroidea has a number of cellular types, such as bladder amoebocytes, filiform amoebocytes, pigmented cells, small spherical corpuscles, large spherical corpuscles, fusiform cells, hyaline plasma cells, flagellated cells and cells with spicules (1) (Cheng, 1984). However, the set of distinguished types depends on the classification methodology. A conventional description of marine invertebrate hemocytes and coelomocytes and the description-based classification include cytological characteristics (cell cytoplasm granularity, nuclear-cytoplasmic rela- 

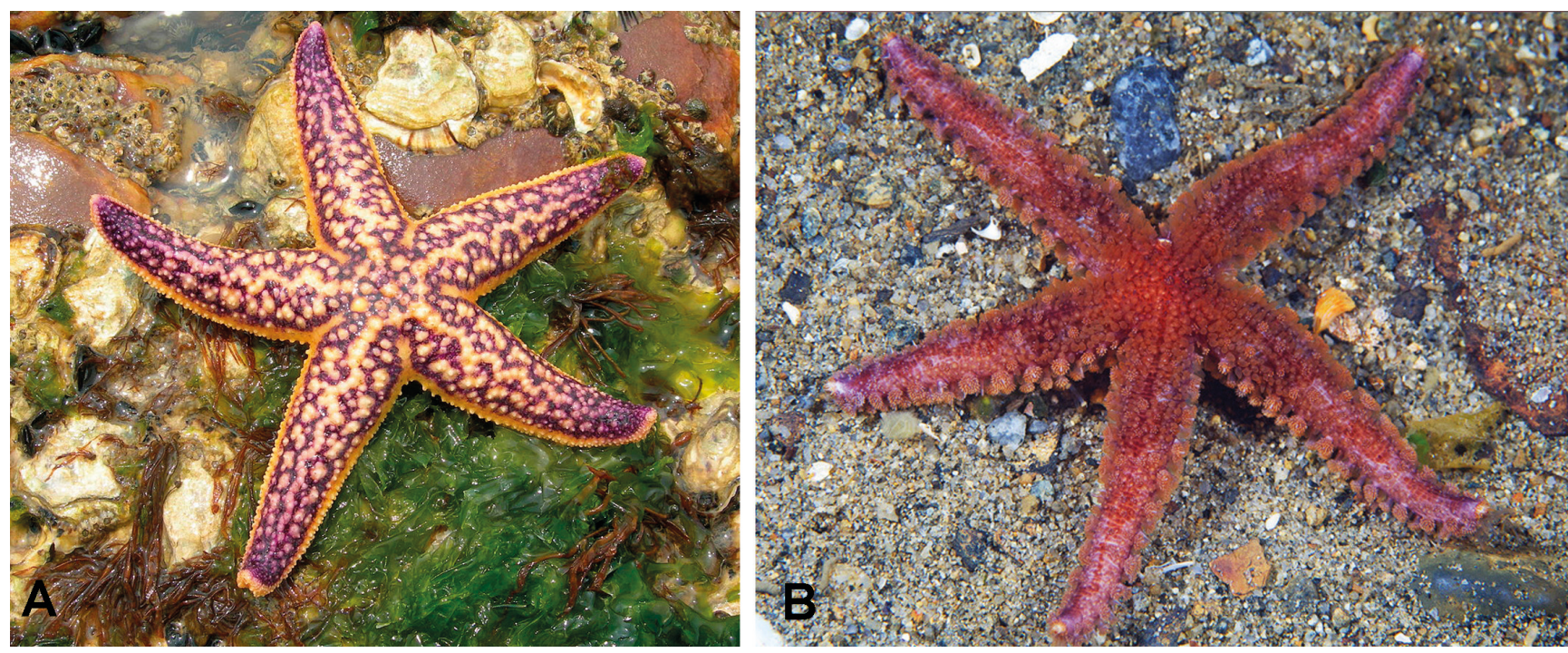

Fig. 1. A: Asterias amurensis, B: Lysastrosoma anthosticta.

tionships, and nuclear chromatin structure), biochemical parameters (e.g., the presence or absence of alkaline phosphatase and other enzymes), and functional characteristics (ability for phagocytosis and adhesion to the substrate) (Hine, 1999). However, hemolymph and coelomic cells of many invertebrates are quite poorly specialized; in some invertebrates, transformations of one cell type to another have been observed (Fisher, 1986; Dyrynda, Pipe, and Ratcliffe, 1997), which complicates topologization and intraspecific and interspecific comparisons of immune cells. The enzyme level, cytoplasm granularity, and other morphofunctional characteristics may vary depending on the functional state of an organism (Perez and Fontanetti, 2011). The above listed characteristics are commonly used for description and classification of immune cells, while the system of differentiating characteristics, which refers to the morphology of spread cells and reflects the cell response to a substrate, often uses only basic characteristics, such as the area (Adema, Harris, and van Deutekom-Mulder, 1992), or statistically nonformalizable descriptions (including terms such as pseudopodia, lamellipodia, etc.). At the same time, differences in the morphology of spread cells may have a biological sense similar to that of the conventional morphometric parameters of hemolymph and coelomic fluid cells. The spread cell shape is formed through the interaction among components of a composite matrix-receptor-cytoskeleton complex. Differences in the cell shape may reflect variations in the functional state of cells (Kolyuchkina and Ismailov, 2011), degree of adhesion to the substrate (Rioult, Lebel, and Le Foll, 2013), diversity of cell surface receptors (Chen and Bayne, 1995), and composition or dynamics of the cytoskeleton structure (Chernyavskikh, Fedorova, Thanh, and Quyet, 2012), both in one species in experiment and control and in different species.
The separated flattened cells of investigated invertebrates (Fig. 1) can be attributed to agranular cells, sufficiently monotypic from the point of view of classical cytological classification (Fig. 2), but forming a series of distinctly different patterns of cellular shapes with time. The substrate-immune cell interaction is a dynamic process. Therefore, a reasonable question arises: how reliably does a measurement made at one point in time characterize the species-specific morphological features of invertebrate immune cells, and how species-specific is the behavioral dynamics of invertebrate immune cells?

\section{Materials and methods}

\section{MATERIAL PREPARATION}

The study was performed on 1186 coelomocytes of the Asterias amurensis starfish (Northern Pacific Seastar) (Echinodermata, Asteroidea) (Lutken, 1871) and on 1008 coelomocytes of Lysastrosoma anthosticta (Echinodermata, Asteroidea) (Fisher, 1922). Animals were collected in the Peter the Great Bay (Sea of Japan, Russia). Immediately after collection, coelomic fluid was sampled from the starfish coelomic cavity using a syringe, immediately placed onto glass coverslips, and incubated for $2,5,15$, and $60 \mathrm{~min}$. Then, the glasses with adhered cells were fixed with a $4 \%$ formaldehyde solution in seawater. After fixation, the cells were stained with hematoxylin and eosin, dehydrated, and embedded in Canada balsam for a light microscopy study. Adherent cells were photographed using a 10 megapixel digital camera of a Zeiss Axiovert 200M Apotome microscope, displayed on a tablet computer screen, and drawn directly from the screen onto transparent films that were then scanned. Both silhouette and contour two-dimensional images 


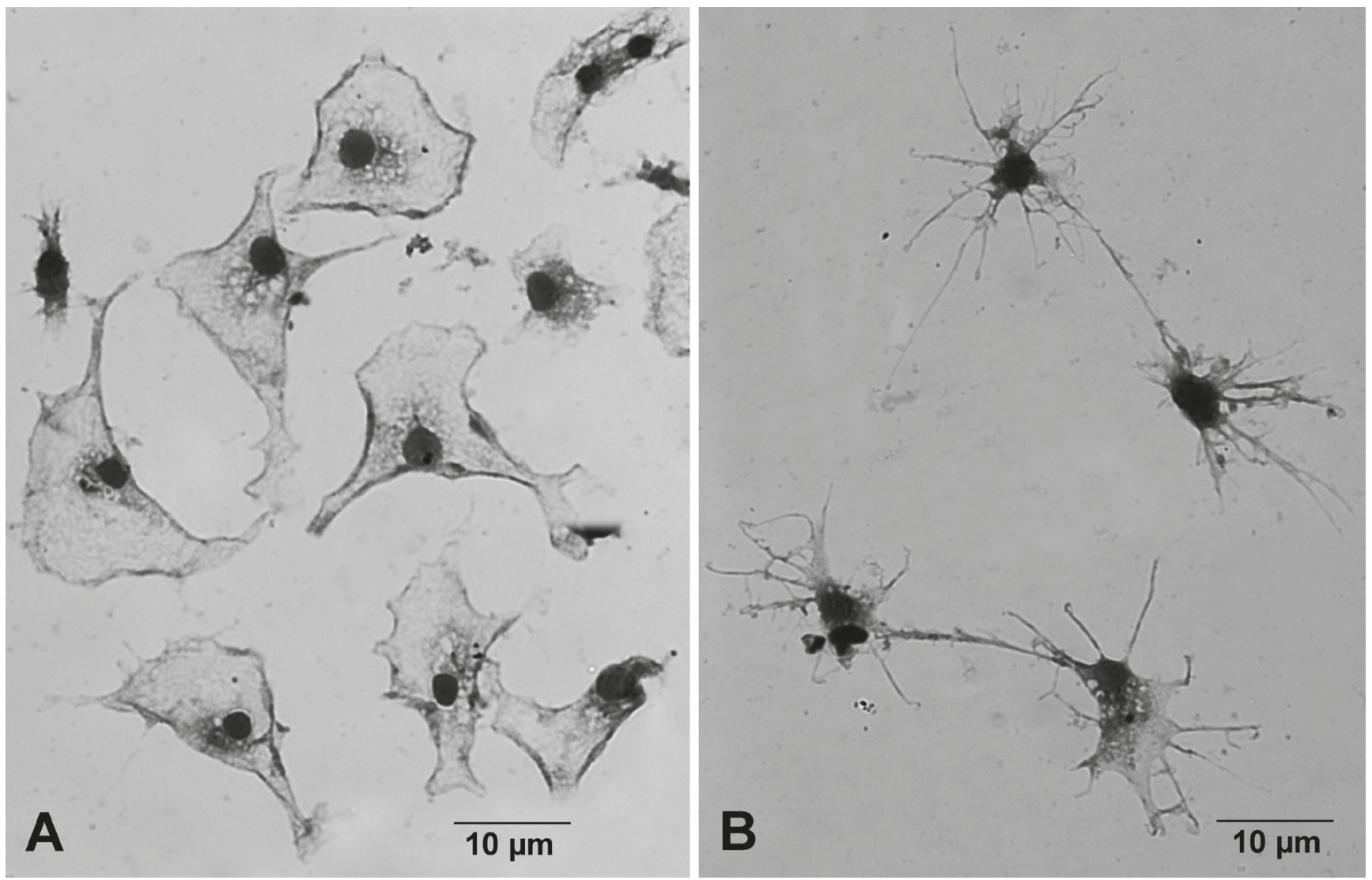

Fig. 2. Flattened coelomocytes: A: Asterias amurensis, B: Lysastrosoma anthosticta.

of flattened cells were analyzed. A single pixel outline of the outer cell boundary was used in contour images. Cell images were digitized and converted to one-bit format.

\section{PARAMETERIZATION}

Linear parameters were calculated using ImageJ $1.41 \mathrm{im}$ age analysis software; a fractal analysis was performed using a FracLac 2.5 plug-in for the ImageJ 1.41 image analysis software. A total of 39 parameters were examined; of these, 10 parameters were selected for use, including seven linear and three nonlinear parameters.

\section{Linear parameters:}

Area; Circularity: $4 \pi \times$ area / perimeter ${ }^{2}$, (Circ); The ratio of cell area in the outer half of the bounding circle to the area of the cells in the inner half of bounding circle, (in50/out50); Hull's Perimeter - perimeter of the convex hull drawn around the object, (Hull'sPer); Diameter of Bounding Circle - bounding circle is calculated using the maximum span across or else the three points defining the smallest circle around the convex hull, (DiamBoundCirc); Density = Foreground Pixels $/$ Hull Area, (Density); Perimeter of cell, (Per);

Nonlinear parameters:

Lacunarity $\mathrm{L}(\mathrm{F}$ (foreground mass $))=(\Sigma(\mathrm{F} \Lambda)) /$ GRIDS - lacunarity based on the variation in pixels per box summarized over all grid orientations for an image, " $\mathrm{F}$ " refers to foreground pixels per box $=(\Sigma(\mathrm{F} \Lambda))$ / GRIDS, (LF); fractal dimension of contour images of cells calculated as follows: Mean D $=\Sigma(\mathrm{D}) /$ GRIDS (D = slope $(\ln$ (Boxes with Foreground Pixels) $/ \ln (\varepsilon))$, where $\varepsilon-$ box size or scale, the average DB (box-counting fractal dimension) from multiple box counting scans, each delivering its own DB, based on a different orientation in the same image of the same series of grid calibers, (outMeanD); Mean Local Fractal Dimension - the average dimension calculated on the basis of multiple sampling an image randomly or systematically and defining the local fractal dimension of various parts of contour images of cells, (outMeanLFD).

\section{STATISTICAL ANALYSIS}

All analyses were performed using NCSS 2007 and STATISTICA 10 statistical software.

The correlation between parameters was measured using Pearson's linear correlation analysis. The scatterplots of pair-wise correlations were also examined to reveal spurious correlations due to outliers (Gordon, 1999). In each group of strongly and significantly correlated parameters $(R \geq 0.8$ at $p<0.05)$, only one parameter was selected to assure that the respective aspect of 

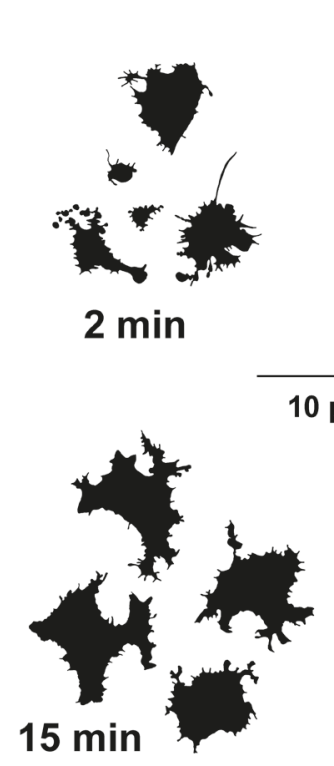

A

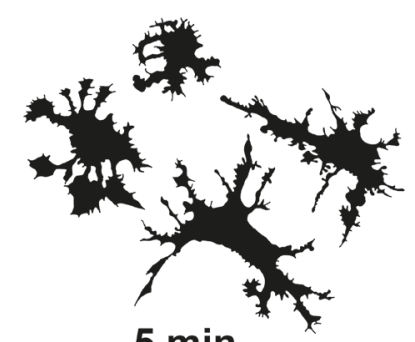

$5 \mathrm{~min}$

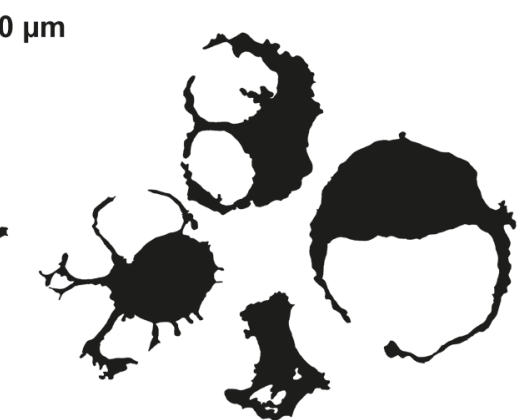

$60 \mathrm{~min}$

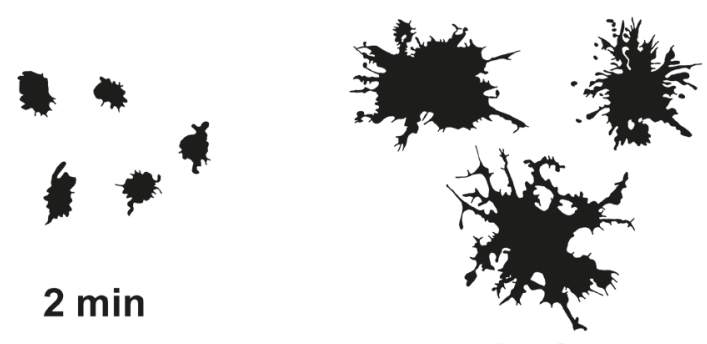

$5 \mathrm{~min}$

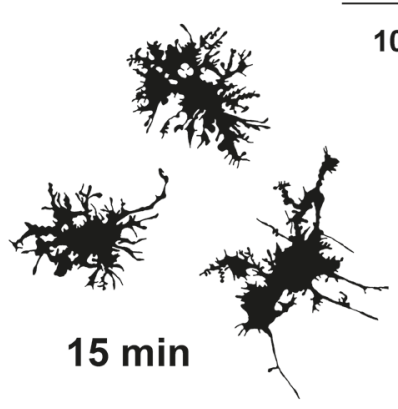

B

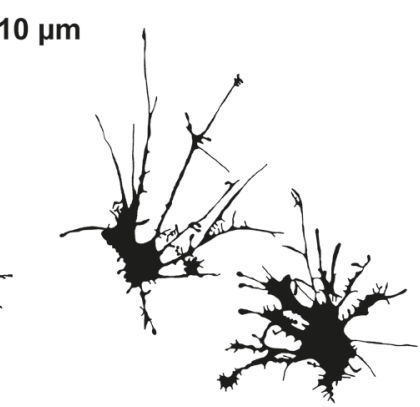

$60 \mathrm{~min}$

Fig. 3. Morphology of A: Asterias amurensis coelomocytes, B: Lysastrosoma anthosticta coelomocytes after 2, 5, 15, and 60 min of cultivation.

cell morphology was adequately, but non-redundantly, represented (Schweitzer and Renehan, 1997).

Fisher's LSD Multiple-Comparison Test is a singlestep multiple comparison procedure that we used to find means that were significantly different from each other. This test compares all possible pairs of means, and is based on a studentized range distribution (q). When doing all pairwise comparisons, this method is considered the best available when confidence intervals are needed.

\section{Results and Discussion}

All adhered coelomocytes of both echinoderm species had an optically transparent basophilic cytoplasm, without granules, and a round non-fragmented nucleus, differing only in features of the external morphology that changed during cultivation.

\section{Asterias amurensis}

As early as two min after seeding on a glass, spread cells with large and small processes already occurred among numerous poorly branched small cells. Cells fixed five min after spreading were the most heterogeneous group in the experiment. The group included both small poorly branched cells and cells of a very complex structure, with long processes covered by second order microprocesses, branched processes, and processes with terminal extensions (Fig. 3A). At the fifth min of cultivation, the spreading dynamics of A.amurensis coelomocytes was characterized by a distinctive change in the cell morphology, with a significant decrease in values of the Circ and Density parameters, reflecting the degree of roundness and the density of space filling by the cell, respectively. In the same time interval, we observed a dramatic increase in the fractal parameters characterizing the overall spatial cell complexity (outMeanD, outMeanLFD) and lacunarity (LF) describing the heterogeneity of space filling by the cell (Fig. $4 \mathrm{c}, \mathrm{e}, \mathrm{m}, \mathrm{o}, \mathrm{r}$; Table 1). This set of characteristics shows an increase in the spatial complexity and asymmetry of the cell, which usually characterizes actively moving or intensively spreading cells. By the 15th min, Circ and Density increased again up to a level comparable to that observed at the second min of cultivation. In turn, fractal parameters of cells decreased down to a level comparable to that observed at the second min of cultivation, continuing to decrease at a slower rate until the 60 th $\mathrm{min}$. That is, by the 15 th $\mathrm{min}$ of cultivation, the spatial complexity of cell morphology dropped again; the number, length, and complexity of processes reduced; the cell shape became more "regular" and indiscrete and often was better circumscribed by the circle; cells had a small number of thin and long processes or a large number of small processes uniformly covering the external cell contour. Nevertheless, the area, like the convex hull and cell bounding circle (Hull'sPer, DiamBoundCirc), continued to increase throughout the entire cultivation period, which indicates the continuing spreading process occurring simultaneously with the described retraction of some processes (Fig. 4 a, g, i). After 60 min of cultivation, the number of small cellular processes decreased further; a small number of large remaining processes lost their sharpness; the microsculpture of cell boundaries became simpler. However, a morphotype absent at earlier stages of cultivation emerged 

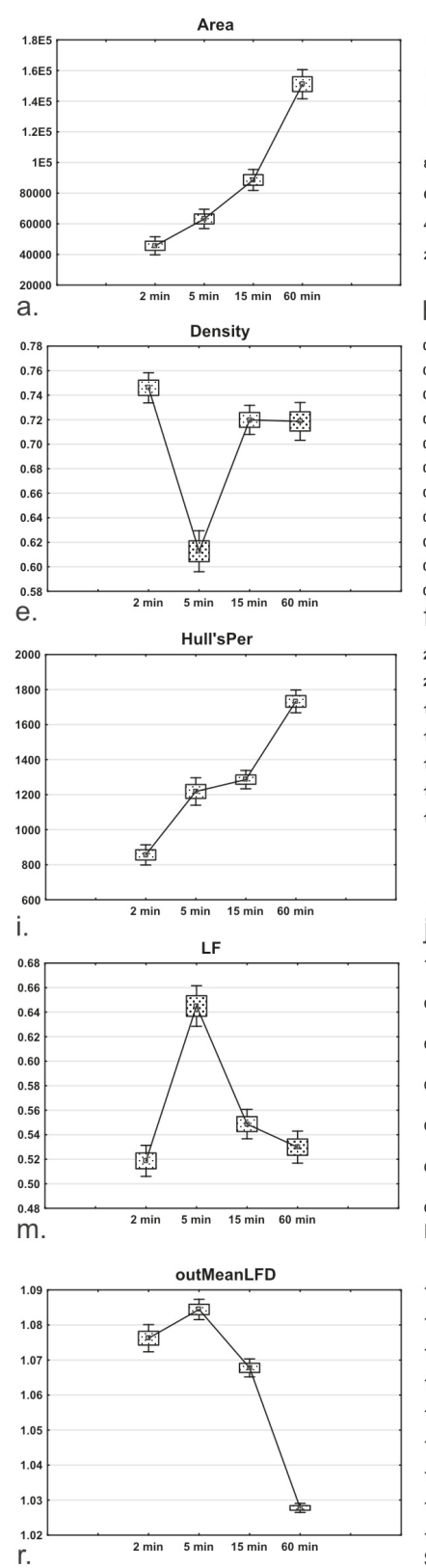

Asterias amurensis
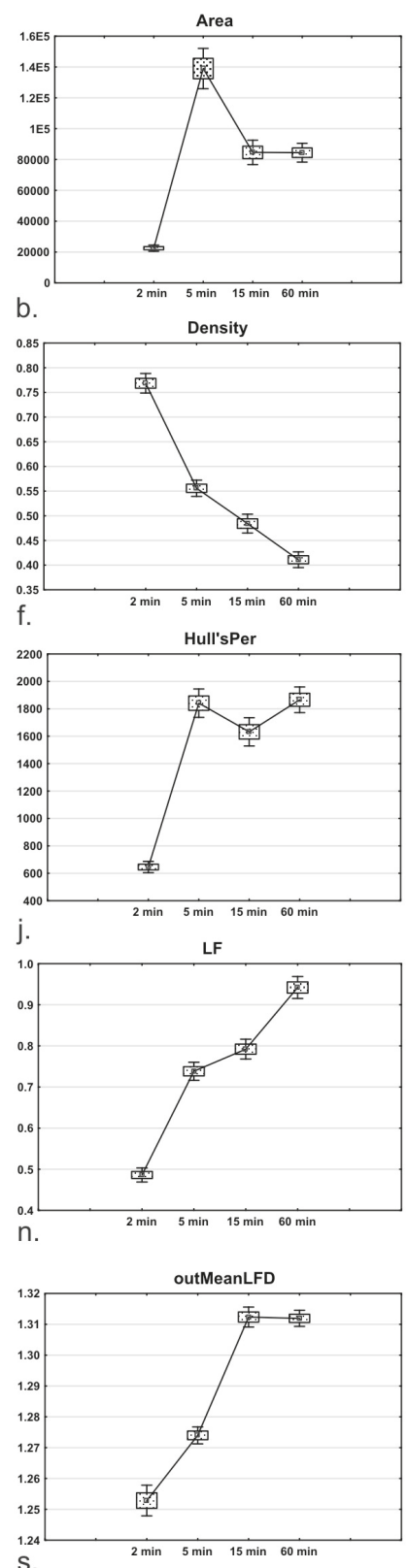

Lysastrosoma anthosticta
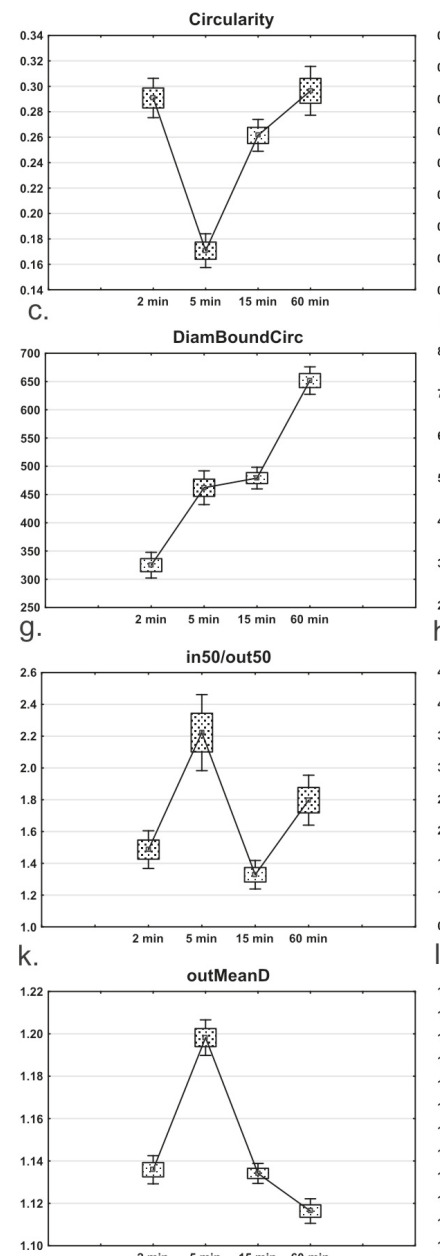

o.

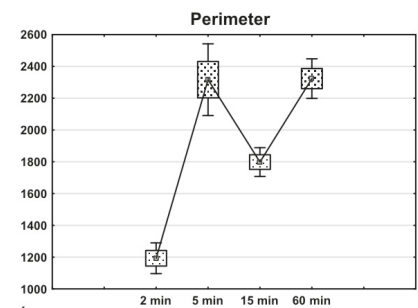

t.

Asterias amurensis
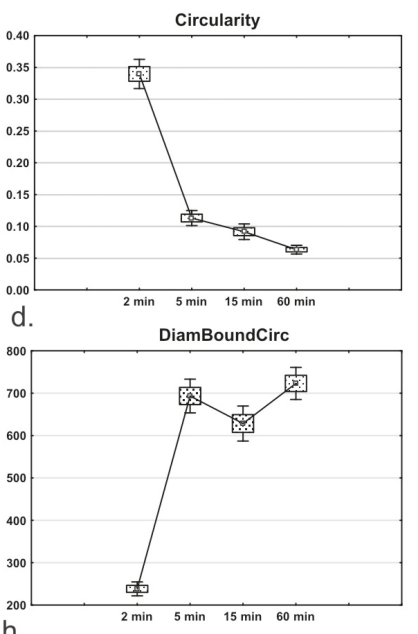

h. $\quad$ in50/out50
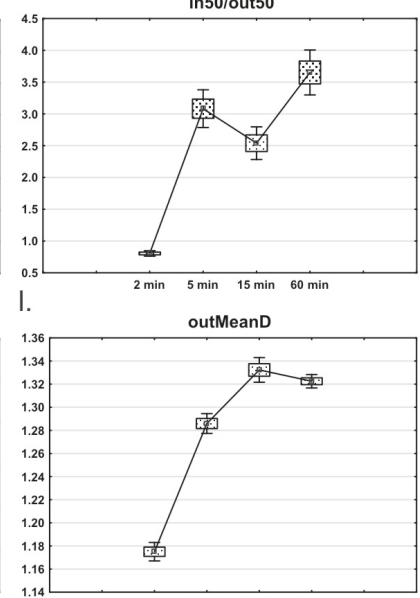

p.

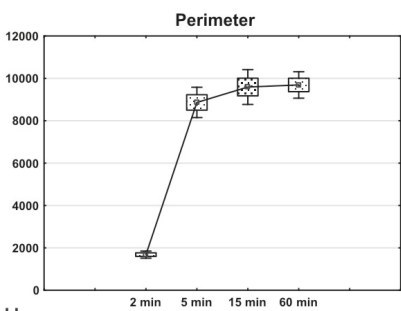

u.

Lysastrosoma anthosticta

Fig. 4. Mean values of selected morphological parameters of Asterias amurensis and Lysastrosoma anthosticta coelomocytes after 2, 5, 15, and 60 min of cultivation. a - Area, A. amurensis; b - Area, L. anthosticta; c- Circularity, A. amurensis; d - Circularity, L. anthosticta; e - Density, A. amurensis; f - Density, L. anthosticta; g - DiamBoundCirc, A. amurensis; h - DiamBoundCirc, L. anthosticta; I - Hull's Per, A. amurensis; j Hull's Per, L. anthosticta; $\mathrm{k}$ - in50/out50, A. amurensis; I - in50/out50, L. anthosticta; m - LF, A. amurensis; $\mathrm{n}$ - LF, L. anthosticta; o - outMeanD, A. amurensis; $\mathrm{p}$ - outMeanD, L. anthosticta; $\mathrm{r}$ - outMeanLFD, A. amurensis; s - outMeanLFD, L. anthosticta; $\mathrm{t}$ - Perimeter, A. amurensis; $\mathrm{u}$ Perimeter, L. anthosticta.

at this stage - cells with bent processes looking as if they delineated circle segments. Partial retraction of the spread cytoplasm at the 60th min of cultivation resulted in the disappearance of certain regions of the cell body; there remained elements of region boundaries in the form of bent pseudopodia delineating the boundaries. The emergence of these morphological structures resulted in the fact that in50/out50 and Perimeter values that had sharply increased by the fifth min and decreased by the 15th min increased again by the 60th min of cultivation (Fig. $4 \mathrm{k}, \mathrm{t}$ ). The Perimeter increase indicates elongation of the total cell boundary length, which is achieved through the emergence of a small number of large processes with a simple shape. In turn, the in50/ out50 parameter is sensitive to the emergence of even a single sufficiently long process that will reduce the filling ratio between the outer and inner parts of the cell bounding circle. These large morphologically indiscrete 
processes do not increase the overall cell spatial complexity and, therefore, do not increase parameters of the fractal dimension that continues decreasing by the 60th min. However, the emerging structures that increase the overall image heterogeneity somewhat resist the lacunarity reduction tendency, which leads to unreliability of lacunarity differences between the 15th and 60th min of cultivation.

\section{Lysastrosoma anthosticta}

Two minutes after seeding on the substrate, Lysastrosoma anthosticta coelomocytes are almost non-flattened cells with a small number of very short processes. However, by the fifth min of cultivation, cells acquire a large number of irregularly shaped processes that grow, branch, and are covered by microspikes by the 15 th min. By the 60th min, not numerous and unbranched, but longer, thin, and chaotically directed processes begin to visually dominate in the shape of cells (Fig. 3B). The Density value for coelomocytes significantly decreases throughout the entire cultivation period. In turn, the outMeanD and outMeanLFD parameters increase by the 15 th min of cultivation, while the in 50/out50 and Perim- eter parameters sharply increase by fifth min of cultivation, remaining without further significant changes. The Area value sharply increases by the fifth min, decreases by the 15th min, and then remains unchanged (Fig. 4 b, f, l, p, s, u; Table 1).

An increase in the values of Area, fractal dimensions (outMeanD and outMeanLFD), and Perimeter and Density until the fifth min indicates a continuing spreading and increased cell branching. The 15th min of cultivation is characterized by a drop in the Area value, with a simultaneous increase in the Density value and an increase in the fractal dimension, which may indicate only an increase in the spatial complexity of cells due to the development of new processes, with simultaneous retraction of the cell body and wide processes.

An increase in LF, in50/out50, DiamBoundCirc, and Hull'sPer values, a decrease in the Density value, and constant fractal dimensions and areas of cells between the 15th and 60th min of cultivation may indicate elongation of terminal processes that do not significantly contribute to the overall area and spatial complexity of the cell, but increase values of the cell bounding circle and convex hull as well as increase the heterogene-

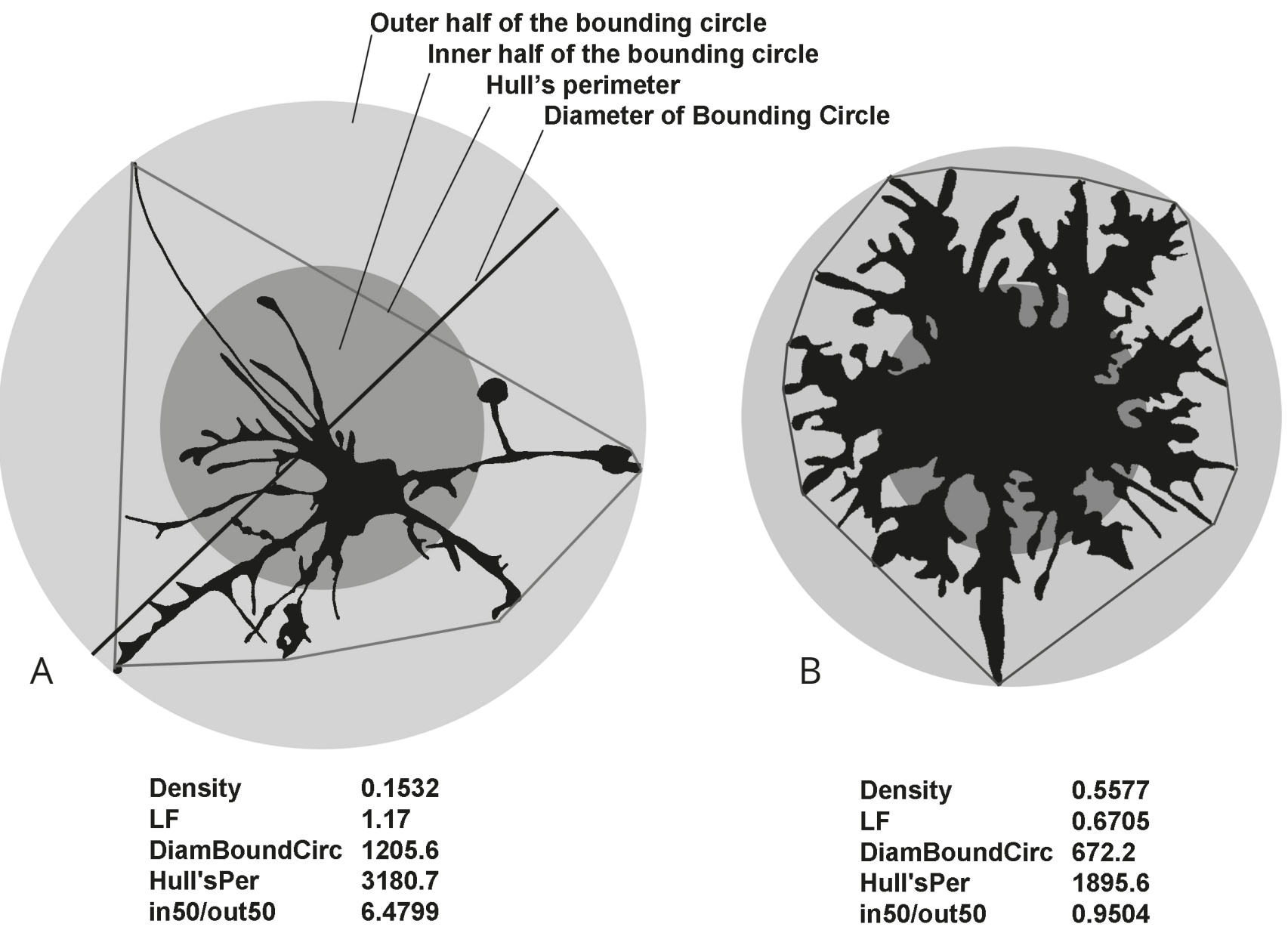

Fig. 5. Cells with a greater (a) and smaller (b) length of terminal processes and appropriate values of linear and quasi-fractal morphological parameters. 
Table 1. Mean values and standard errors of selected morphological parameters of Asterias amurensis and Lysastrosoma anthosticta coelomocytes. The values in the cells of the table filled with gray do not have significant differences according to the Fisher's LSD Multiple-Comparison Test

\begin{tabular}{|c|c|c|c|c|c|c|c|c|}
\hline \multirow{2}{*}{$\begin{array}{l}\text { Parameters } \\
\text { Mean, +/-S. E. }\end{array}$} & \multicolumn{2}{|c|}{$2 \mathrm{~min}$} & \multicolumn{2}{|c|}{$5 \mathrm{~min}$} & \multicolumn{2}{|c|}{$15 \mathrm{~min}$} & \multicolumn{2}{|c|}{$60 \mathrm{~min}$} \\
\hline & aa & la & aa & la & aa & la & aa & la \\
\hline Area $\left(\mu m^{2}\right)$ & $\begin{aligned} & 8.5 \\
&+/-0.7\end{aligned}$ & $\begin{array}{c}202.88 \\
+/-69.6\end{array}$ & $\begin{array}{r}72.25 \\
+/-4.9\end{array}$ & $\begin{aligned} & 32.8 \\
&+/-1.05\end{aligned}$ & $\begin{array}{c}51.5 \\
+/-2.5\end{array}$ & $\begin{aligned} & 53.9 \\
+ & +-2.77\end{aligned}$ & $\begin{array}{c}30.19 \\
+/-0.87\end{array}$ & $\begin{array}{l}54.06 \\
+/-2.4\end{array}$ \\
\hline Circularity & $\begin{array}{c}0.290 \\
+/-7.94 \mathrm{E}-03\end{array}$ & $\begin{array}{c}0.339 \\
+/-1.31 \mathrm{E}-02\end{array}$ & $\begin{array}{c}0.170 \\
+/-7.39 \mathrm{E}-03\end{array}$ & $\begin{array}{l}0.113+/- \\
7.62 \mathrm{E}-03\end{array}$ & $\begin{array}{c}0.261 \\
+/-7.41 \mathrm{E}-03\end{array}$ & $\begin{array}{c}9.15 \mathrm{E}-02 \\
+/-7.43 \mathrm{E}-03\end{array}$ & $\begin{array}{c}0.297 \\
+/-6.207 E-03\end{array}$ & $\begin{array}{c}6.33 \\
+/-6.47 \mathrm{E}-03\end{array}$ \\
\hline Density & $\begin{array}{c}0.74 \\
+/-8.906 \mathrm{E}-03\end{array}$ & $\begin{array}{c}0.76 \\
+/-1.47 \mathrm{E}-02\end{array}$ & $\begin{array}{c}0.6 \\
1+/-8.28 \mathrm{E}-03\end{array}$ & $\begin{array}{c}0.55 \\
+/-8.54 \mathrm{E}-03\end{array}$ & $\begin{array}{c}0.71 \\
+/-8.31 \mathrm{E}-03\end{array}$ & $\begin{array}{c}0.48 \\
+/-8.32 \mathrm{E}-03\end{array}$ & $\begin{array}{c}0.71 \\
+/-6.95 \mathrm{E}-03\end{array}$ & $\begin{array}{c}0.41 \\
+/-7.25 \mathrm{E}-03\end{array}$ \\
\hline outMeanD & $\begin{array}{c}1.13 \\
+/-4.06 \mathrm{E}-03\end{array}$ & $\begin{array}{c}1.17 \\
+/-6.72 \mathrm{E}-03\end{array}$ & $\begin{array}{c}1.19 \\
+/-3.77 \mathrm{E}-03\end{array}$ & $\begin{array}{c}1.28 \\
+/-3.89 \mathrm{E}-03\end{array}$ & $\begin{array}{c}1.13 \\
+/-3.79 \mathrm{E}-03\end{array}$ & $\begin{array}{c}1.33 \\
+/-3.79 \mathrm{E}-03\end{array}$ & $\begin{array}{c}1.11 \\
+/-3.17 \mathrm{E}-03\end{array}$ & $\begin{array}{c}1.32 \\
+/-3.306 \mathrm{E}-03\end{array}$ \\
\hline outMeanLFD & $\begin{array}{c}1.07 \\
+/-1.51 \mathrm{E}-03\end{array}$ & $\begin{array}{c}1.25 \\
+/-2.51 \mathrm{E}-03\end{array}$ & $\begin{array}{c}1.08 \\
+/-1.41 \mathrm{E}-03\end{array}$ & $\begin{array}{c}1.27 \\
+/-1.45 \mathrm{E}-03\end{array}$ & $\begin{array}{c}1.06 \\
+/-1.41 \mathrm{E}-03\end{array}$ & $\begin{array}{c}1.31 \\
+/-1.41 \mathrm{E}-03\end{array}$ & $\begin{array}{c}1.02 \\
+/-1.18 \mathrm{E}-03\end{array}$ & $\begin{array}{c}1.31 \\
+/-1.23 \mathrm{E}-03\end{array}$ \\
\hline LF & $\begin{array}{c}0.51 \\
+/-1.09 \mathrm{E}-02\end{array}$ & $\begin{array}{c}0.48 \\
+/-0.018\end{array}$ & $\begin{array}{c}0.64 \\
+/-1.01 \mathrm{E}-02\end{array}$ & $\begin{array}{c}0.73 \\
+/-1.04 \mathrm{E}-02\end{array}$ & $\begin{array}{c}0.54 \\
+/-1.01 \mathrm{E}-02\end{array}$ & $\begin{array}{c}0.79 \\
+/-1.02 \mathrm{E}-02\end{array}$ & $\begin{array}{c}0.53 \\
+/-8.52 \mathrm{E}-03\end{array}$ & $\begin{array}{c}0.94 \\
+/-8.88 \mathrm{E}-03\end{array}$ \\
\hline DiamBoundCirc & $\begin{array}{r}324.9 \\
+/-17.8\end{array}$ & $\begin{array}{c}238.2 \\
+/-29.5\end{array}$ & $\begin{array}{c}461.9 \\
+/-16.6\end{array}$ & $\begin{array}{l}693.3 \\
+/-17.1\end{array}$ & $\begin{array}{c}479.1 \\
+/-16.6\end{array}$ & $\begin{array}{l}628.3 \\
+/-16.7\end{array}$ & $\begin{array}{l}651.8 \\
+/-13.9\end{array}$ & $\begin{array}{c}722.9 \\
+/-14.5\end{array}$ \\
\hline Hull'sPer & $\begin{array}{l}856.1 \\
+/-45.7\end{array}$ & $\begin{array}{l}645.7 \\
+/-75.7\end{array}$ & $\begin{array}{l}1218.1 \\
+/-42.5\end{array}$ & $\begin{array}{l}1841.2 \\
+/-43.8\end{array}$ & $\begin{array}{l}1285.9 \\
+/-42.6\end{array}$ & $\begin{array}{l}1631.9 \\
+/-42.7\end{array}$ & $\begin{aligned} & 1733 \\
&+/-35.7\end{aligned}$ & $\begin{array}{l}1865.9 \\
+/-37.2\end{array}$ \\
\hline Perimeter $(\mu \mathrm{m})$ & $\begin{array}{r}16,4 \\
+/-3.6\end{array}$ & $\begin{array}{l}23,2 \\
+/-6\end{array}$ & $\begin{array}{c}31.9 \\
+/-3.4\end{array}$ & $\begin{array}{l}122.4 \\
+/-3.4\end{array}$ & $\begin{array}{c}24.8 \\
+/-3.4\end{array}$ & $\begin{array}{l}132.4 \\
+/-3.44\end{array}$ & $\begin{array}{c}32 \\
+/-2.8\end{array}$ & $\begin{array}{r}133.8 \\
+/-2.98\end{array}$ \\
\hline in50/out50 & $\begin{aligned} & 1.48 \\
&+/-0.13\end{aligned}$ & $\begin{array}{c}0.80 \\
+/-0.22\end{array}$ & $\begin{aligned} & 2.22 \\
&+/-0.12\end{aligned}$ & $\begin{aligned} & 3.08 \\
&+/-0.12\end{aligned}$ & $\begin{aligned} & 1.32 \\
&+/-0.12\end{aligned}$ & $\begin{array}{r}2.53 \\
+/-0.12\end{array}$ & $\begin{array}{c}1.79 \\
+/-0.105\end{array}$ & $\begin{aligned} & 3.65 \\
&+/-0.11\end{aligned}$ \\
\hline
\end{tabular}

ity (LF) and decrease the image density. The increased length of terminal processes increases the values of the cell bounding circle (DiamBoundCirc) and convex hull (Hull's Per), enhances the disproportionality in the filling of the outer and inner halves of the cell bounding circle by the cell, thus increasing the in $50 /$ out50 parameter, increases non-uniformity of the filling of the celloccupied space, which affects the lacunarity (LF) value, and decreases the cell density, increasing the number of background pixels inside the cell convex hull (Fig. 5).

Therefore, the spreading dynamics of studied cells is species-specific and dramatically differs in the studied species. Among the common dynamical features of cells from both animal species, we may distinguish the most active transformation during the first five min after seeding cells on the substrate, with a sharp increase in the parameters describing the dimensional characteristics and complexity of cell morphology, although the intensity of morphological changes and the initial parameter values differ in both species. Spreading of Asterias amurensis coelomocytes occurs for an hour of cultivation, but the maximum structural complexity manifests only at the fifth min, and the secondary formation of processes with different morphology occurs after $60 \mathrm{~min}$ of cultivation. In turn, the typical morphology of Lysastrosoma anthosticta cells forms by the 15th min of cultivation, and then only some rearrangements of the cell microsculpture and elongation of processes continue. The dynamics of changes in most

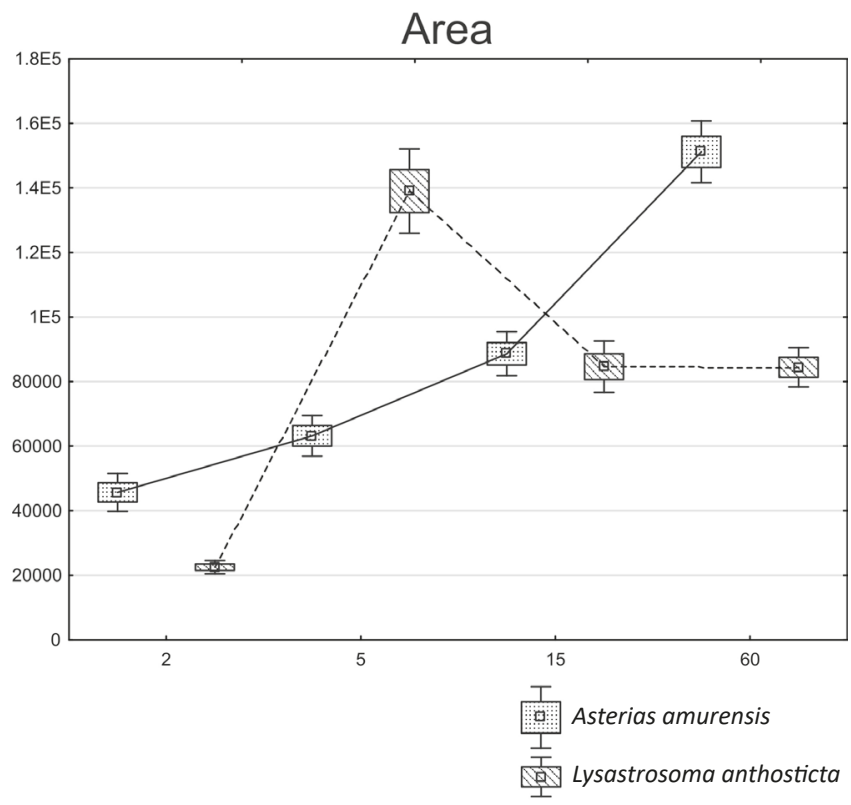

Fig. 6. Dynamics of changes in the Area parameter of Asterias amurensis and Lysastrosoma anthosticta coelomocytes after 2, 5, 15, and 60 min of cultivation. 
parameters is different in cells of both animal species; therefore, immune cells of two animal species differ in at least three parameters in the multiparametric space of morphological features at any moment of short-term cultivation (Table 1). However, the time trends of several parameters intersect. If the cell morphology is described with only one parameter, there may be intervals where the morphology of coelomocytes from two studied species will not significantly differ. For example, a common morphological parameter, the area, in immune cells of the studied species has two intersections of the mean parameter values around the fourth and 15th min after seeding on the substrate (Fig. 6). Therefore, at least two selected parameters should be used for a reliable morphological description of cells at any time point of the primary cultivation process. It is not necessary to monitor the time dynamics of spreading for describing the species-specific morphology because a single time point is sufficient. However, morphology of cells either from different species or from different experiments with the same species should be compared at a similar time point, starting with the fifth min after cell seeding on the substrate.

\section{Conclusions}

The species-specificity of invertebrate immune cell morphology includes the species-specificity of cell behavior on the substrate. The differences in cell behavior are based on the differences in functional dynamics of cells, in particular, responses to peculiarities of the external environment (Mermelstein, Rebello, Amaral, and Costa, 2003; Paine, Christensen, Toews, and Simon, 1994), extracellular matrix (Dolatshahi-Pirouz et al., 2011; Vignaud et al., 2012), and genetic, biochemical, and physiological features of cells (Borges et al., 2011; Chauhan, Lou, Zheng, and Lang, 2011), including the cytoskeleton structure (Welsh and Saleem, 2012) and the qualitative and quantitative composition of cell adhesion molecules (Domínguez-Giménez, Brown, and Martin-Bermudo, 2007). The cell activity analysis evaluates interspecies differences cell immunity functioning. Multiparametric comparison that includes a set of classical and quasifractal morphological parameters allows a detailed description of the temporal dynamics of cell morphology changes. This description may be added to a description of the species-specificity of invertebrate immune cells. But in the case of significant differences in the cell dynamics, the species-specificity is also revealed during morphometry of cells at a single time point if a morphological description includes at least two selected parameters that describe the dimensional characteristics and spatial complexity of the spread cell and significantly differ in study species.

\section{References}

Adema, C. M., Harris, R. A., and van Deutekom-Mulder, E. C. 1992. A comparative study of hemocytes from six different snails: Morphology and functional aspects. Journal of Invertebrate Pathology 59:24-32. https://doi. org/10.1016/0022-2011(92)90107-F

Borges, R. M., Lamers, M. L., Forti, F. L., Santos, M. F., and Yan C. Y. 2011. Rho signaling pathway and apical constriction in the early lens placode. Genesis 49:368-379. https://doi.org/10.1002/dvg.20723

Chauhan, B. K., Lou, M., Zheng, Y., and Lang, R. A. 2011. Balanced Rac1 and RhoA activities regulate cell shape and drive invagination morphogenesis in epithelia. Proceedings of the National Academy of Sciences, U S A 108(45):18289-18294. https://doi.org/10.1073/ pnas. 1108993108

Chen, J.H., and Bayne, C.J. 1995. Hemocyte adhesion in the California mussel (Mytilus californianus): regulation by adenosine. Biochimica et Biophysica Acta - Molecular Cell Research 1268:178-184. https://doi.org/10.1016/01674889(95)00074-3

Cheng, T. C. (Ed.). 1984. Comparative Pathobiology. Invertebrate Blood. Vol.6. Springer Science+Business Media. New York. https://doi.org/10.1007/978-1-4684-4766-8

Chernyavskikh, S. D., Fedorova, M. Z., Thanh, V. V., and Quyet, D. H. 2012. Reorganization of actin cytoskeleton of nuclear erythrocytes and leukocytes in fish, frogs, and birds during migration. Cell and Tissue Biology 6:348-352. https://doi.org/10.1134/S1990519X12040025

Dolatshahi-Pirouz, A., Kolind, J. K., Bünger, C., Kassemd, M., Foss, M., and Besenbacher, F. 2011. Cell shape and spreading of stromal (mesenchymal) stem cells cultured on fibronectin coated gold and hydroxyapatite surfaces. Colloids and Surfaces B: Biointerfaces 84:18-25. https:// doi.org/10.1016/j.colsurfb.2010.12.004

Domínguez-Giménez, P., Brown, N. H., and Martín-Bermudo, M. D. 2007. Integrin-ECM interactions regulate the changes in cell shape driving the morphogenesis of the Drosophila wing epithelium. Journal of Cell Science 120:1061-1071. https://doi.org/10.1242/jcs.03404

Dyrynda, E. A., Pipe, R. K., and Ratcliffe, N. A. 1997. Sub-populations of haemocytes in the adult and developing marine mussel, Mytilus edulis, identified by use of monoclonal antibodies. Cell and Tissue Research 289:527-536. https://doi.org/10.1007/s004410050898

Fisher, W. S. 1986. Structure and functions of oyster hemocytes; pp. 25-35 in Immunity in invertebrates. M. Brehelin, J. M. Arcier, N. Boemare, J. R. Bonami, C. P. Vivares, (Eds.) Berlin; Heidelberg: Springer-Verlag. https://doi. org/10.1007/978-3-642-70768-1_3

Gordon, A. D. 1999. Classification. Boca Raton, FL: Chapman and Hall, CRC.

Hine, P. M. 1999. The inter-relationships of bivalve haemocytes. Fish Shellfish Immunology 9:367-385. https://doi. org/10.1006/fsim.1998.0205

Kalitnik, A. A., Karetin, Y. A., Kravchenko, A. O., Khasina, E. I., and Yermak, I. M. 2017. Influence of carrageenan on cytokine production and cellular activity of mouse peritoneal macrophages and its effect on experimental endotoxemia. Journal of Biomedical Materials Research Part A 105:1549-1557. https://doi.org/10.1002/jbm.a.36015

Karetin, Y. A., and Pushchin, I. I. 2015. Analysis of the shapes of hemocytes of Callista brevisiphonata in vitro (Bivalvia, Veneridae). Cytometry A 87:773-776. https://doi. org/10.1002/cyto.a.22676

Karetin, Y. A. 2016. Nonlinear analysis of hemocyte morphology in the sea stars Aphelasterias japonica (Bell, 1881), 
Patiria pectinifera (Muller et Troschel, 1842), and the bivalve Callista brevisiphonata (Carpenter, 1864). Russian Journal of Marine Biology 42:275-282. https://doi. org/10.1134/S1063074016040052

Karetin, Y. and Pushchin, I. 2017. Analysis of the shapes of coelomocytes of Aphelasterias japonica in vitro (Echinodermata: Asteroidea). Protoplasma 254:1805-1811. https://doi.org/10.1007/s00709-017-1078-z

Kolyuchkina, G.A. and Ismailov, A.D. 2011. Morphofunctional features of bivalve mollusks during experimental contamination of the medium with heavy metals. Oceanology 51:804-813. https://doi.org/10.1134/ S0001437011050092

Mermelstein, C.S., Rebello, M. I., Amaral, L. M., and Costa, M. L. 2003. Changes in cell shape, cytoskeletal proteins and adhesion sites of cultured cells after extracellular $\mathrm{Ca}^{2+}$ chelation. Brazilian Journal of Medical and Biological Research 36:1111-1116. https://doi.org/10.1590/ S0100-879X2003000800018

Paine, R. 3rd, Christensen, P., Toews, G. B., and Simon, R. H. 1994. Regulation of alveolar epithelial cell ICAM-1 expression by cell shape and cell-cell interactions. American Journal of Physiology 266:L476-L484. https://doi. org/10.1152/ajplung.1994.266.4.L476
Perez, D. G. and C. S. Fontanetti. 2011. Hemocitical responses to environmental stress in invertebrates: a review. Environmental Monitoring and Assessment 177:437-447. https://doi.org/10.1007/s10661-010-1645-7

Ratner, S. and Vinson, S. B. 1983. Phagocytosis and encapsulation: cellular immune responses in Arthropoda. American Zoologist 23:185-194. https://doi.org/10.1093/ icb/23.1.185

Rioult, D., Lebel, J.-M., and Le Foll, F. 2013. Cell tracking and velocimetric parameters analysis as an approach to assess activity of mussel (Mytilus edulis) hemocytes in vitro. Cytotechnology 65:749-758. https://doi.org/10.1007/ s10616-013-9558-2

Schweitzer, L. and Renehan, W. E. 1997. The use of cluster analysis for cell typing. Brain Research Protocols 1:100-108. https://doi.org/10.1016/s1385-299x(96)00014-1

Vignaud, T., Galland, R., Tseng, Q., Blanchoin, L., Colombelli, J., and Théry, M. 2012. Reprogramming cell shape with laser nano-patterning. Journal of Cell Science 125:2134-2140. https://doi.org/10.1242/jcs.104901

Welsh, G. I. and Saleem M. A. 2012. The podocyte cytoskeleton - key to a functioning glomerulus in health and disease. Nature Reviews Nephrology 8:14-21. https://doi. org/10.1038/nrneph.2011.151 